might be based on a decrease in the patient's cellular resistance after laparotomy, on coincidence, or on mechanical reactivation of latent peritoneal tuberculosis. They favour the last possibility.

An earlier study of the natural history of tuberculous peritonitis lends support to this theory. ${ }^{7}$ In 47 patients the diagnosis was established by percutaneous biopsy in 30 , by peritoneoscopy in 10, and by laparotomy in 7. Culture of ascitic fluid was positive for acid-fast bacilli in 39 . The patients were very fully investigated by chest radiography, barium enema and barium meal studies, intravenous pyelography, and salpingography. In three patients only there was evidence of a tuberculous lesion in the lung parenchyma, but there was no evidence at all of infection in the intestine or Fallopian tubes. Pleural effusions were present in 15, and in 6 there was evidence of pericarditis. It seemed probable to the authors, therefore, that the tuberculous peritonitis was not caused by spread of the infection from other organs but was more likely to be due to activation of latent tuberculous disease of the peritoneum or mesentery, ${ }^{7}$ a conception of the aetiology of tuberculous peritonitis which had been suggested some years earlier. ${ }^{8}$

The onset of abdominal swelling, fever, and ascites some weeks after an abdominal operation might suggest intraabdominal abscess, obstruction, bacterial or amoebic peritonitis, or some inflammation of the liver or interference with portal circulation. ${ }^{6}$ It may be wise to consider also the possibility of tuberculous peritonitis, the diagnosis of which may be confirmed by needle biopsy or other form of peritoneal investigation before resorting to a second laparotomy. 679 .

1 Befeler, B., and Baum, G. L., American Revierv of Respiratory Disease, 1967, 96, 977.

2 Pearson, R. S. B., Postgraduate Medical fournal, 1954, 30, 159

3 Stead, W. W., American Review of Respiratory Disease, 1965, 91, 811.

4 Allison, S. T., New England fournal of Medicine, 1955, 252, 862.

5 Warthin, T. A., American fournal of Medical Sciences, 1953, 225, 421

- Rafoth, R., Morse, R., Edwards, L. D., Jupa, J., and Levin, S., Scandinavian fournal of Infectious Diseases, 1972, 4, 139.

7 Singh, M. M., Bhargava, A. N., and Jain, K. P., New England fournal of Medicine, 1969, 281, 1091 .

8 Nice, C. M., Diseases of the Chest, 1950, 17, 550.

"Levine, H., Archives of Internal Medicine, 1967, 120, 542.

\section{Teachers and Patients}

A patient going to a hospital, whether as an outpatient or an inpatient, is likely to be worried about his illness. To this concern is added the further threat of a new, strange, unfamiliar, frightening world. $\mathrm{He}$ is in danger of losing his bearings and his self-esteem, or unconsciously thinks he is. The situation may become even more threatening and unfamiliar if he goes to a teaching hospital, and few major hospitals today are not used for teaching undergraduates or postgraduates.

Now the Health Department has published a circular on teaching on patients. ${ }^{1}$ The problems of a patient in a teaching hospital are only an extension of those facing a patient in any hospital, and the Department's circular is an attempt to minimize this extension. Criticism has rightly been levelled at teachers who are insensitive of their patients' fears, an insensitivity which must surely be unintentional and due to lack of imagination. But the same criticism can also be made against doctors who are not teaching. It is essential to create an ambience in which the patient can express his anxieties. This takes time. It may be quicker but in the long term is less therapeutically and less economically effective to prescribe an antacid and an antispasmodic and forbid smoking for a man of $\mathbf{3 0}$ with a duodenal ulcer than to seek and help modify his fears and aspirations, his frustrations at work and in the home, and the worries that may be gnawing at his guts.

Within the last decade the doctor-patient relationship in hospitals has improved by virtue of understanding, courtesy, good manners, and mutual respect. Further improvement will come with better education of the doctor, irrespective of his specialty, because every illness-even a broken leghas its accompanying but often unexpressed fears: "Shall I ever be able to walk normally again? Shall I be handicapped in my work? Shall I be able to ski again? My uncle died of a lung clot after breaking a hip, shall I? Isn't a fracture worse than a broken bone?" These are aspects that the student, undergraduate or postgraduate, must learn and hear discussed between the teacher and his patient. Most doctors unconsciously anticipate these unvoiced fears, make the time to discuss them, and through identification with the sufferer risk the today unfashionable accusation of having a good bedside manner, which is not synonymous with being kind but incompetent.

Though teaching undoubtedly poses special problems, the presence or absence of students is of secondary importance to the relationship established between the patient and the teaching doctor. The Department's circular properly emphasizes the right of the patient to opt out of the teaching situation, but in tone it is rather a negative document of implied "don'ts," and some of its recommendations are so impractical as to prompt the question when its authors were last in a teaching hospital either as patients or as doctors. They may have consulted the Department of Education and Science, but did they consult any medical teachers?

It is safe advice that patients should be forewarned of what to expect in a teaching hospital, but in practice this is of limited value because all too readily the patient, more concerned with his own illness, forgets what he is given to read or is told. Under present pressures how many general practitioners can follow the recommendation to explain to their patients what may or may not happen at a teaching hospital; and how will a general practitioner know which outpatient clinics, when he rofers a patient, are attended by students? Nor are hospital receptionists the right people to give sympathetic explanations to the patient. In urban areas, in the face of commercial competition in the labour market, these kind, often underpaid women seldom have the time or knowledge to explain the pros and cons of teaching to the line of patients, despite the appointments system, queueing at the reception desk of a busy clinic.

The Department's advice on how best to manage the situation when a patient attending an outpatient clinic elects to be seen without students being present is acceptable if due warning is given by the patient, but it does raise practical problems for which no solution is proffered. Should the consultant send the students away for a cup of coffee, or should he hunt around for a non-existent unoccupied room in the outpatient department? In practice it is less disturbing to all concerned if the patient is initially seen in complete privacy by a registrar and for the consultant to go in afterwards and review the history and physical findings with the patient and the registrar. This problem is understandably greater when the patient has a psychiatric disorder or when the letter of referral indicates that the disorder- 
impotence, for example-is likely to be charged with emotional overtones. Such patients are best seen in a non-teaching clinic.

In the wards the difficulties are less. The interpatient relationships, from which emerges a sort of esprit de corps, seldom fail to release the patient from the inhibitions surrounding teaching. Curtains must be drawn and, as in outpatient clinics, candlewick dressing gowns or attractive turkish towelling used to diminish any embarrassment for the patient. Discussion on differential diagnosis, prognosis, and treatment is best carried out away from the patient's bed and out of earshot of other patients. But afterwards it is essential that the teacher returns to have a personal word with the patient, who may feel threatened by the mere fact that he has been excluded from the conversation.

The Department's suggested texts to be sent to prospective outpatients and inpatients of a teaching hospital are actually less inspiring than those already used by some teaching hospitals. No mention is made of the benefits that may accrue to the patient by attending a teaching hospital, something that is well appreciated in the United States and for which there is statistical evidence in this country. Even if it were not politic to mention this tactfully, patients know that students must be taught and doctors further trained. They appreciate too that most advances in clinical medicine emanate from hospitals where research and teaching are pursued. As the circular does indeed point out, they can be readily made to understand that they themselves are helping the advance of medicine.

1 Department of Health and Social Security, Teaching on Patients, $\mathrm{HM}(73) 8$.

\section{Sudden Whitening of Hair}

An event as dramatic as sudden whitening of hair is inevitably surrounded by a rich folk lore, to which exaggeration and inaccurate reporting have contributed. For over a century the experts have disputed whether it is ever possible, many stating categorically that hair once formed is dead and inaccessible to such a change. But in recent years several fully authenticated cases have been reported in which a mechanism is apparent.

J. E. Jelinek ${ }^{1}$ has recently reviewed many of the fascinating earlier reports from historical and literary sources, and A. J. Ephraim ${ }^{2}$ has given a full account of medical reports over the past 150 years. The historical cases that have come down to us nearly always occurred in dramatic circumstances. Even in Shakespeare's day sudden whitening of hair was attributed to shock. Sir Thomas More's hair apparently turned white during the night before his execution and General Gordon's during the final stages of the seige of Khartoum. Among other cases are some memorable for their symbolism, such as that of a man whose hair turned suddenly white when he woke up to find himself alone with an appropriately grizzly bear. Even more remarkable is the tale of a 24-year-old officer whose hair on only half of his beard and scalp turned white after a night of carnal dissipation with a mulatto. Even in 1940 a textbook is quoted as saying that rape of young girls is a common cause of sudden whitening. Many of these early reports are poorly authenticated, and though fairly rapid whitening of hair can be believed the exact timing and relationship to the reported cause has to be treated with considerable scepticism.

Various theories have been put forward to account for this phenomenon. Vitiligo and other depigmenting diseases may at times spread rapidly on the skin, may affect the hair, and may sometimes apparently be associated with emotional or neurological disorders. It can cause whitening of hair over some months, but could hardly cause overnight whitening of already pigmented hair. To account for rapid whitening it has been suggested that air bubbles may suddenly be forced into the hair matrix. Such a mechanism is responsible for the paler segments of the banded hair of pili annulati, but again it seems incredible that this could affect the whole hair shaft overnight, and it has not been convincingly demonstrated.

In alopecia areata regrowth of hair is often white, and no doubt this could account for some cases where the timing had not been carefully noted. However, the most plausible theory is that sudden whitening of hair is due to some disease process which selectively causes the dark hairs to be shed, sparing the white. Grey hair is an admixture of fully p'gmented and white hairs, and even as little as $5 \%$ or less of residual white hairs could make a respectable covering. That the white hairs are often spared in the patches of alopecia areata has long been known, ${ }^{3}$ and any dermatologist could expect to see this at least once or twice every year. Rarely alopecia areata may have an explosive onset involving the whole scalp, and in the past 15 years several cases have been recorded leading to sudden whitening of hair. ${ }^{14}$ It is noteworthy that an acute shock was not apparent in these cases. This is in accord with the current ideas that emotional factors are not primarily concerned in the pathogenesis of alopecia areata, though their precise role is still disputed, 56 for there is a lingering impression, unsubstantiated by accurate statistics, that acute emotional disturbances can provoke attacks of alopecia areata in a few patients. The difference in behaviour of white and dark hairs in alopecia areata must surely hold some clue to its aetiology.

1 Jelinek, J. E., Bulletin of the New York Academy of Medicine, 1972, 48, 1003.

2 Ephraim, A. J., Archives of Dermatology, 1959, 79, 228.

3 Sabouraud, R., Maladies du Cuir Chevelu, V. Les syndromes Alopéciques. Pelades tt Alopécies en Aires. Paris, Mason, 1929.

Klingmüller, V. G., Dermatologica, 1958, 117, 84.

5 Macalpine, I., British fournal of Dermatology, 1958, 70, 117.

- Reinhold, M., British Medical fournal, 1960, 1, 846.

\section{Postoperative Empyema and Survival in Lung Cancer}

Despite advances in surgical technique and postoperative care the five-year survival rate in lung cancer remains disappointingly low. Retrospective examination of the notes of patients who have had the good fortune to live for five or more years after pneumonectomy can only rarely give clues to why surgery was successful. In most circumstances the great number of uncontrolled variables that are part of any random series of cancer cases are such as to render retrospective studies of little use. However, occasionally this type of study can be rewarding if an unequivocal event appears to have intervened between surgery and the expected progression of the tumour to widespread metastasis.

Empyema was a fairly common complication in the pioneering days of thoracic surgery, but during the last 20 